\title{
Open Surgery Treatment of a Rare Cause of Intestinal Obstruction: Left Paradoudenal Hernia
}

This article was published in the following Dove Press journal:

International Medical Case Reports Journal

\section{Duong Trieu Trieu \\ Quoc Van Le (D) \\ Hien Van Nguyen (D)}

Department of Colon and Rectal Surgery, The 108 Military Central Hospital, Hanoi, Vietnam
Correspondence: Quoc Van Le

Department of Colon and Rectal Surgery, The 108 Military Central Hospital, No. I Tran Hung Dao Street, Bach Dang Ward, Hai Ba Trung District, Hanoi I00000,

Vietnam

Tel +84979966103

Email levanquoch108@gmail.com
Abstract: An internal hernia is the protrusion of visceral contents through a congenital or acquired defect in the peritoneum or mesentery within the abdominal cavity. In approximately $0.6-5.8 \%$ of patients with small intestinal obstruction, the cause is internal hernia, with paraduodenal hernias accounting for approximately $40 \%$ of cases. Here, we present the case of a 51-year-old man diagnosed with obstruction of the small intestine caused by a hernia on the left side of the duodenum. The treatment involved returning the bowel loops to the normal position and closing the hernia pocket using Prolene 2.0 sutures. The duration of the surgery was $30 \mathrm{~min}$. Five days later, the patient's condition was stable and he was discharged from the hospital; at the 32-month postoperative follow-up, he remained in stable condition with no recurrence. An abdominal computed tomography scan is valuable for early diagnosis of paraduodenal hernia in the absence of complications, and the cause can be identified and the bowel returned to the normal position by endoscopic surgery, with closure of the hernia pocket if the intestine does not stick to the pocket.

Keywords: open surgery, paraduodenal hernia, internal hernia, intestinal obstruction

\section{Introduction}

An internal hernia is the protrusion of visceral contents through a congenital or acquired defect in the peritoneum or mesentery within the abdominal cavity. It may occur naturally (eg, Winslow hernia), or as a result of fetal mesenteric abnormalities. In approximately $0.6-5.8 \%$ of patients with small intestinal obstruction, the cause is internal hernia, with paraduodenal hernias accounting for approximately $40 \%$ cases. ${ }^{1,2}$ The symptoms of left-side paraduodenal hernia are nonspecific, ${ }^{3}$ ranging from intermittent abdominal pain (when the hernia is not obstructed) to acute abdominal pain (when there is strangulation of the hernia pocket along with bowel necrosis); therefore, diagnosing this pathology is difficult. Abdominal computed tomography (CT) is a useful diagnostic tool, and surgical management options are laparoscopic or open surgery. ${ }^{4}$ Here we present a case of small intestinal obstruction caused by a left-side paraduodenal hernia that was diagnosed prior to surgery based on CT scan results and then successfully treated by surgery.

\section{Case Presentation}

At around 5 a.m. on November 4, 2017, a 51-year-old Vietnamese male patient without any history of abdominal surgery was admitted to the emergency department with acute abdominal pain in the left abdomen accompanied by nausea, 


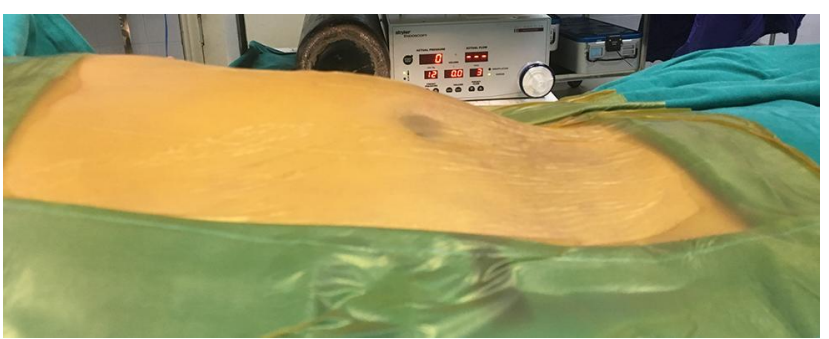

Figure I Photograph of the abdominal distension on the left side.

vomiting, and abdominal distention. The patient had been experiencing occasional abdominal cramps after meals that lasted for about $15 \mathrm{~min}$, and subsided when he was in the supine position. His vital signs were normal. There was an $8 \times 8$-cm mass in the lower left abdominal quadrant, and the patient reported acute pain when pressure was applied to left mid-abdominal wall (Figure 1).

Laboratory results were normal. The abdominal X-ray showed signs of air fluid, and the CT scan of the abdominal cavity revealed hernias on the left side of the duodenum with slightly dilated small bowel straps concentrated in the upper left quadrant between the stomach and pancreas (Figure 2).

The patient was diagnosed with intestinal obstruction caused by a hernia on the left side of the duodenum. Open surgery was selected in favor of laparoscopic surgery as the treatment because the small intestine was attached to the hernia pocket and could not be processed through endoscopy. The lesion was an $8 \times 8$-cm hernia pocket, herniated organs were the small intestine straps with congestion

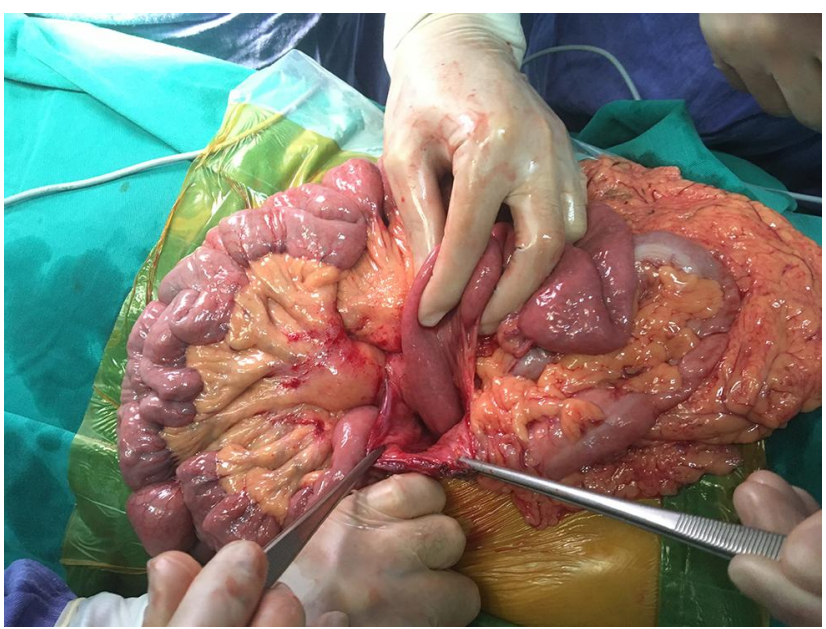

Figure 3 Photograph of the left hernia hole.

lesions; and no ischemia or necrosis was observed, although the bowel above the site of obstruction was enlarged (Figure 3). The treatment involved returning the bowel loops to the normal position and closing the hernia pocket with Prolene 2.0 (Figure 4). The duration of the surgery was $30 \mathrm{~min}$. Five days after surgery, the patient's condition was stable and he was discharged from the hospital. At the 32-month postoperative follow-up, the patient remained stable and there was no recurrence.

\section{Discussion and Conclusions}

Despite being a rare condition, paraduodenal hernias are a common type of internal hernias. ${ }^{5}$ Neubauer was the
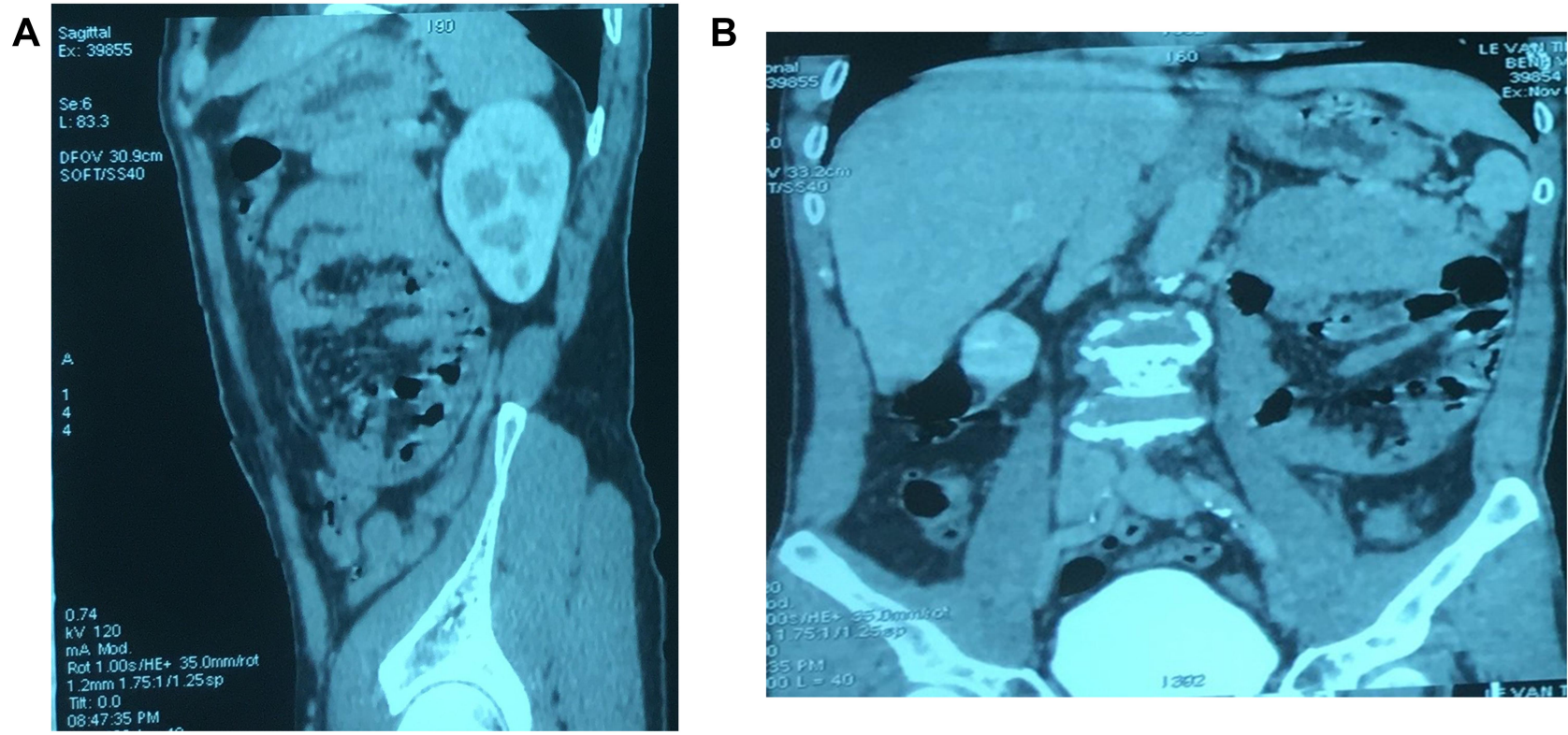

Figure 2 Image from a computed tomography scan showing an unusual pocket (A and $\mathbf{B})$. 

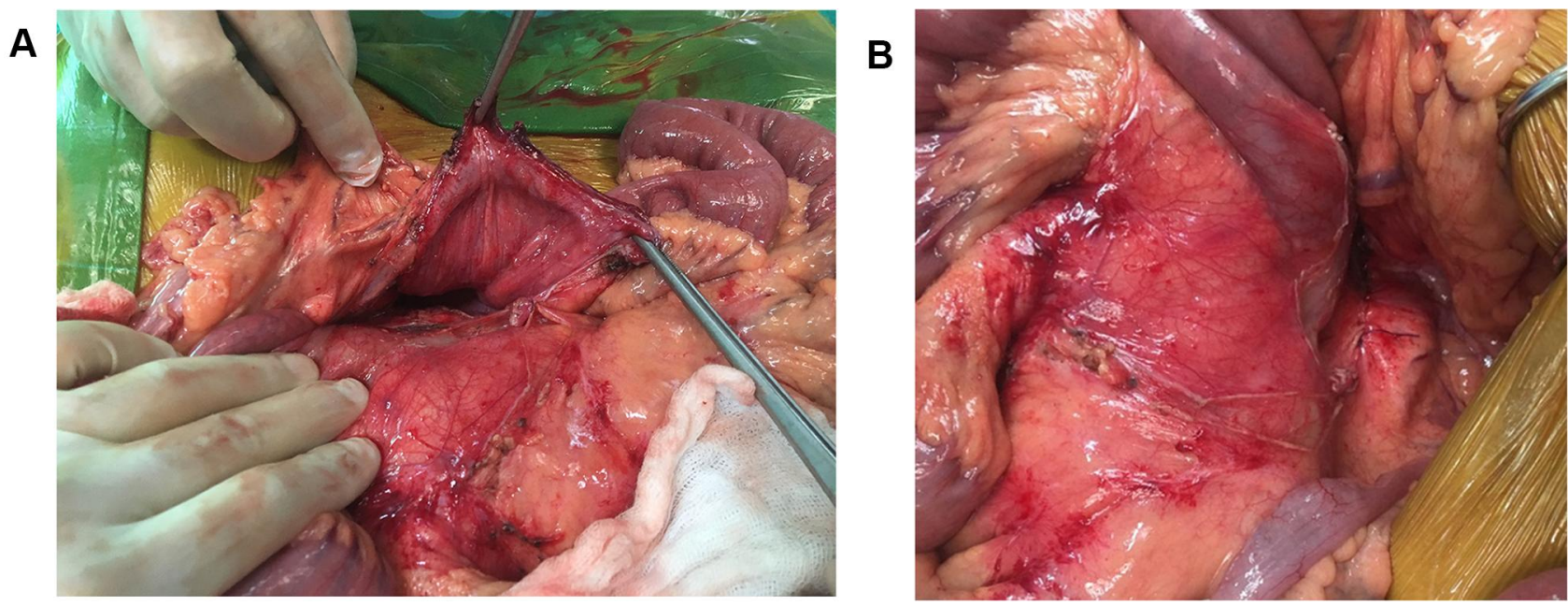

Figure 4 Photographs of the bowel before $(\mathbf{A})$ and after $(\mathbf{B})$ closure of the herniated left side of the duodenum.

first to describe a hernia around the duodenum during an autopsy in 1786. In 1989 and 1890, hernias around the duodenum were classified into 2 types, left and right. The embryonic origin of a right-side hernia resulting from defective or incomplete central rotation was first reported in 1923. In 1935, left paraduodenal hernia was described as a defect involving the fusion of the left colon and mesentery. ${ }^{6}$ In this case, the intestine was observed to have completed rotation, so the left paraduodenal hernia was considered as a defect. Hernias on the left side (Waldeyer hole hernia) are 3 times more common than those on the right side (Landzert hole hernia). ${ }^{7}$ A hernia around the duodenum can occur at any age but usually appears at around 40-60 years old (mean age: 38.5 years), and the male-to-female ratio is $3: 1 .^{8}$ In left paraduodenal hernias, the neck of the sac is limited by the front of the left middle colon branches, and the lower front part is the transverse colon behind the inferior mesenteric veins. ${ }^{9}$

Peri-duodenal hernias have few symptoms, and are mainly detected by laparotomy or autopsy. ${ }^{3}$ The symptoms are often vague - ranging from an uncomfortable feeling to acute intestinal pain - and usually appear after a meal (especially a large one), and the pain often does not subside after changing positions. In the present case, the patient experienced abdominal pain after a long meal, but it should be noted that the pain subsided when he was in the left recumbent position. ${ }^{1}$ Some symptoms associated with periduodenal hernias such as abdominal pain, vomiting, and nausea can lead to a misdiagnosis of peritonitis with biliary tract disease or peptic ulcer. ${ }^{6}$ Symptoms manifest when there is intestinal obstruction and necrosis of the intestine. The most effective diagnostic tool for a hernia around the left duodenum is CT, with a typical image showing the hernia sac containing the intestinal straps at the back of the stomach or compression of the superior mesenteric artery that displaces the mesenteric body to the right and pushes the colon downwards. ${ }^{10}$

Patients with left paraduodenal hernia have a 50\% risk of recurrence throughout their lifetime with a mortality rate of $20-50 \%$ for acute cases. ${ }^{11,12}$ Therefore, surgery is proposed after diagnosis regardless of whether there are symptoms. This can be either laparoscopic or open surgery with the basic aim of releasing the hernia, and correcting the anatomic defect. ${ }^{13}$ There are many reports of cases that were safely and effectively treated by laparoscopic surgery. However, open surgery is recommended in cases where the hernia presents with anemia, necrosis, or adhesion in the hernia sac, with laparotomy being the best choice in cases of unknown bowel obstruction. ${ }^{4,9,14,15}$

In conclusion, left-side paraduodenall hernias are rare and typically manifest as ileus or necrotic bowel symptoms. An abdominal CT scan is valuable for early diagnosis when there are no complications. Endoscopic surgery can resolve the hernia and return the bowel to the normal position, with closure of the hernia pocket if the intestine does not stick to the pocket.

\section{Data Sharing Statement}

All data generated or analysed during this study are included in this published article. 


\section{Ethics Approval and Consent to Participate}

Written informed consent was obtained from the patient for publication of this case report and accompanying images. The need for ethics approval was waived because of the case report design.

\section{Consent for Publication}

The patient gave consent for publication.

\section{Author Contributions}

All authors made substantial contributions to conception and design, acquisition of data, or analysis and interpretation of data; took part in drafting the article or revising it critically for important intellectual content; agreed to submit to the current journal; gave final approval of the version to be published; and agree to be accountable for all aspects of the work.

\section{Funding}

The authors received no financial support for the research, authorship, and/or publication of this article.

\section{Disclosure}

The authors report no conflicts of interest in this work.

\section{References}

1. Newsom BD, Kukora JS. Congenital and acquired internal hernias: unusual causes of small bowel obstruction. Am J Surg. 1986;152 (3):279-285. doi:10.1016/0002-9610(86)90258-8

2. Martin LC, Merkle EM, Thompson WM. Review of internal hernias: radiographic and clinical findings. AJR Am J Roentgenol. 2006;186 (3):703-717. doi:10.2214/AJR.05.0644
3. Yun MY, Choi YM, Choi SK, Kim SJ, Ahn SI, Kim KR. Left paraduodenal hernia presenting with atypical symptoms. Yonsei Med J. 2010;51(5):787-789. doi:10.3349/ymj.2010.51.5.787

4. Uematsu T, Kitamura H, Iwase M, et al. Laparoscopic repair of a paraduodenal hernia. Surg Endosc. 1998;12(1):50-52. doi:10.10 07/s004649900591

5. Peltokallio P, Kalima TV. Left paraduodenal hernia. Am J Surgery. 1968;115(3):367-370. doi:10.1016/0002-9610(68)90162-1

6. Gokcal F, Akdamar F, Celenk Y, Akdemir Z. A case report of left paraduodenal hernia diagnosed preoperatively and treated laparoscopically. Turk J Surg. 2018;34(3):243-246. doi:10.5152/ turkjsurg.2017.3322

7. Virich G, Davies W. A massive left paraduodenal fossa hernia as an unusual cause of small bowel obstruction. Ann R Coll Surg Engl. 2010;92(4):W7-9. doi:10.1308/147870810X12659688851997

8. Al-Khyatt W, Aggarwal S, Birchall J, Rowlands TE. Acute intestinal obstruction secondary to left paraduodenal hernia: a case report and literature review. World J Emerg Surg. 2013;8(1):5. doi:10.1186/ 1749-7922-8-5

9. Palanivelu C, Rangarajan M, Jategaonkar PA, Anand NV, Senthilkumar K. Laparoscopic management of paraduodenal hernias: mesh and mesh-less repairs. A report of four cases. Hernia. 2008;12 (6):649-653. doi:10.1007/s10029-008-0376-y

10. Doishita S, Takeshita T, Uchima Y, et al. Internal hernias in the era of multidetector ct: correlation of imaging and surgical findings. Radiographics. 2016;36(1):88-106. doi:10.1148/rg.2016150113

11. Blachar A, Federle MP, Brancatelli G, Peterson MS, Oliver JH 3rd, Li W. Radiologist performance in the diagnosis of internal hernia by using specific CT findings with emphasis on transmesenteric hernia. Radiology. 2001;221(2):422-428. doi:10.1148/radiol.2212010126

12. Zonca P, Maly T, Mole DJ, Stigler J. Treitz's hernia. Hernia. 2008;12 (5):531-534. doi:10.1007/s10029-008-0339-3

13. Bartlett MK, Wang C, Williams WH. The surgical management of paraduodenal hernia. Ann Surg. 1968;168(2):249-254. doi:10.1097/ 00000658-196808000-00010

14. Wakabayashi M, Kono S, Takahashi T. Laparoscopic repair of acute small bowel obstruction due to left paraduodenal hernia: a case report. Int J Surg Case Rep. 2018;51:194-199. doi:10.1016/j.ijscr. 2018.08.050

15. Kwan B, Theodore JE, Wong J. Laparoscopic paraduodenal hernia repair with bioabsorbable mesh: a case of a novel technique for a rare cause of bowel obstruction. Int J Surg Case Rep. 2020;70:1-4. doi:10.1016/j.ijscr.2020.03.035
International Medical Case Reports Journal

\section{Publish your work in this journal}

The International Medical Case Reports Journal is an international, peer-reviewed open-access journal publishing original case reports from all medical specialties. Previously unpublished medical posters are also accepted relating to any area of clinical or preclinical science. Submissions should not normally exceed 2,000 words or 4 published pages including figures, diagrams and references. The manuscript management system is completely online and includes a very quick and fair peer-review system, which is all easy to use. Visit http://www.dovepress.com/testimonials.php to read real quotes from published authors. 